\title{
Hysterical Spinal Paralysis
}

\author{
D. F. Apple, Jr, MD
}

1938 Peachtree Road, Suite 710, NW, Atlanta, GA 30309, USA.

\section{Summary}

Seventeen patients were diagnosed as having hysterical paralysis. Although a variety of patterns of motor and sensory loss were seen, 15 out of 17 patients had normal reflexes, and all the patients had bowel and bladder control, an important diagnostic point. All but 1 were improved after an average 3.8 days hospital stay with 13 being fully recovered. When a patient is encountered with paralysis, normal reflexes and bowel and bladder control, the only initial diagnostic study indicated is routine $X$-rays.

Key words: Hysterical spinal paralysis; Normal reflexes; Bladder control.

Charcot, the French neurologist, developed the early description of hysteria. Freud, one of his pupils, further defined la grand hysterie into four phases: the epileptoid; violent movement; attitudes passionnelles or hallucinatory; and the final delirium (Critchley and Canton, 1984). Hysterical paralysis fits into the hallucinatory phase. Other terms used to describe this disorder are conversion hysteria, conversion reaction, functional hysteria and functional paralysis.

The main feature of an hysterical problem is an alteration or loss of function for which there is no apparent anatomical or physiological explanation. In hysterical paralysis there is loss of sensation and/or motor function in areas of the body relating to the patient's idea of a functional unit rather than in a definite pattern of innervation. Hysteria has traditionally been considered to primarily affect females and, whether male or female, occurs between the ages of 15 and 30.

\section{Patients and methods}

During 1988, the physicians at Shepherd Spinal Center saw 10 patients with a diagnosis of hysterical paralysis. Patients admitted to Shepherd Spinal Center and its associated hospital, Piedmont Hospital, from 1984 to 1988, with the 
Table I

\begin{tabular}{lr}
\hline Fall & 7 \\
MVA & 6 \\
Struck & 2 \\
Misc. & 2 \\
\hline & \\
Table II & 10 \\
\hline Paraplegia & 2 \\
Quadriplegia & 2 \\
Monoplegia, UE & 2 \\
Monoplegia, LE & 1 \\
Diplegia & \\
\hline
\end{tabular}

discharge diagnosis of hysterical paralysis were reviewed. Seventeen records were identified and analysed for sex, age, length of stay, aetiology, physical examination and status on discharge.

\section{Results}

Twelve of the 17 patients were male with an age range of 12 to 43 and an average of 29.4 years. Aetiologies are shown in Table I. Review of the sensory examinations demonstrated 11 to have had normal findings. Six others had variable sensory loss which corresponded to the loss of motor function. All had normal rectal sensation. The results of the motor examinations are shown in Table II. In the 2 patients who were quadriplegic, 1 had touch preserved and the other had normal sensation in all extremities.

Reflexes were evaluated in all cases. They were present in all but 2 and were graded as equal except in 2 patients where they were present but diminished. In both cases where the reflexes were not present, there was an associated high alcohol intake.

All patients had X-ray evaluations, which were normal except for 1 patient who had a T12 minimal compression fracture. Four patients had computerised tomography, 2 a myelogram and 1 a magnetic resonance image, and all were normal. Five patients had elevated blood alcohol, $3 \mathrm{had}$ had a previous episode of paralysis, and 1 had a positive psychiatric history.

Treatment consisted of evaluation and assurance that recovery would occur. At discharge, 14 were normal, 3 had weakness in one leg and 1 patient was transferred from the acute hospital to a psychiatric unit. This patient had no history of trauma, with gradual onset of monoplegia. The average stay was 3.9 days ranging from 1 to 12 days.

\section{Discussion}

Hysteria is diagnosed when there are symptoms out of proportion to anatomical and physiological function. Most investigators believe there is a higher incidence in women. In this series, $70 \%$ were male. In a review by Dickson et al. (1984), 8 of 9 were males and all 4 were males in Watson's report (1982). In 
Delargy's group (1986) 50\% were males and Weingarden's (Weingarden and Lynch, 1984) group of 5 had 4 males. However, in a large series from the Hysterical Paralysis Acupuncture Treatment Center in China (Zhenymg et al., 1987), 56\% were female. In Ziegler's study (1960), of 134 patients with many forms of hysteria, $82 \%$ were female. Although there is not total agreement, it appears that hysterical paralysis is male predominant. Fifteen of these 17 patients had traumatic induced spinal cord injury. Spinal cord injury is a problem of young adult males which may explain the reversed sexual incidence.

Elements of the physical examination are most important. Although any combination of sensory and motor loss can be seen, the predominant clinical pattern in all studies is paraplegia. The critical element in the examinations, as noted by Smith (1926), is reflex function which is almost universally normal. In this series, 2 patients had absent reflexes but the examination was clouded by heavy alcohol intoxication; however, at discharge reflexes had returned. Reflex function in the presence of paralysis should alert an examiner to the possibility that no spinal cord injury exists, suggesting a functional paralysis.

To test motor function the physician can elevate the paralysed limb and let it go. Frequently the limb will remain suspended in space rather than quickly returning to the examination table as it should if truly paralysed. Another test is to place a hand under both heels and perform a straight leg rising test on one side and frequently if there is not a true paralysis, the examiner will feel a pushing down pressure on the unelevated heel.

All of the patients in this series had normal rectal sensation and with intact reflex function had a positive bulbocavernosis reflex. Bowel and bladder control are usually normal, arousing suspicion of the diagnosis of hysterical paralysis. If there is any doubt, urodynamic studies can be obtained.

Regarding diagnostic studies, routine X-rays are all that is required. If the $\mathrm{X}$-rays are normal and the patient has normal reflexes, further evaluation may be delayed for 24 to 48 hours. Most patients show significant improvement during that time and by discharge are normal. In this study approximately $\$ 4000$ worth of unnecessary studies were performed. If the patient's paralysis does not respond in 4 to 5 days, further studies are indicated but probably will be normal.

Treatment is not a problem in the acute case but in those whose symptoms last beyond 7 to 10 days physical therapy (Mackinnon, 1984), functional electrical stimulation (Khalil et al., 1988) and, in the Chinese series (Zhenymg et al., 1987), acupuncture can be helpful. Long term psychiatric intervention may be necessary in chronic cases (Lazare, 1981). In patients with a psychiatric disorder who then develop paralysis, an organic cause must be ruled out prior to attributing the paralysis to the psychiatric problem (Miller et al., 1986).

\section{Conclusion}

In the evaluation of a traumatised patient who presents with paralysis, either paraplegia or quadriplegia, obtain routine X-rays. If the patient has normal reflexes and preserved anal and genital sensation and function, in-depth diagnostic studies such as a CAT scan, myelogram or MRI are not indicated acutely. 


\section{References}

CRITChley EMR, CANTon HE 1984 Charcot's hysteria renaissant. British Medical fournal 289:1785-1788.

Delargy MA, Peatfield RC, Burt AA 1986 Successful rehabilitation in converstion paralysis. British Medical fournal 292:1730-1731.

Dickson H, Cole A, Engel S, Jones RF 1984 Conversion reaction presenting as acute spinal cord injury. The Medical fournal of Australia 141:427-429.

Khalil TM, AbDel-Moty E, Asfour SS et al. 1988 Functional electrical stimulation in the reversal of conversion disorder paralysis. Archives of Physical Medicine and Rehabilitation 69:545-546.

LAZARE A 1981 Current concepts in psychiatry. The New England fournal of Medicine 305:745748.

MACKINNON JL 1984 Physical therapy treatment of a patient with conversion reaction. Physical Therapy 64:687-688.

Miller BL, Benson DF, Goldberg MA, Gould R 1986 Misdiagnosis of hysteria. American Family Physician 34:157-160.

SMith WA 1926 Hysterical paraplegia with contractures. The Piedmont Hospital Bulletin 4:106109.

WatSON N 1982 An outbreak of hysterical paraplegia. Paraplegia 20: 154-156.

WEINGARDEN S, LYNCH C 1984 Functional paralysis mimicking spinal cord injury resulting in admission to a spinal cord injury center. Archives of Physical Medicine and Rehabilitation 65:145-147.

ZHENYMG Z, BINGIREN Y, WEL W 1987 An observation of 1316 cases of hysterical paralysis treated by acupuncture. Fournal of Traditional Chinese Medicine 7:113-115.

ZEIGLER FJ, I MBODEN JB, MEYER E 1960 Contemporary conversion reactions: a clinical study. American fournal Psychiatry 116:9019. 